\title{
Variety in Performance: A comparative Analysis of Recorded Performances of Bach's Sixth Suite for Solo Cello from 1961 to 1998
}

\author{
ALISTAIR SUNG \\ The University of New South Wales \\ DOROTTYA FABIAN \\ The University of New South Wales
}

\begin{abstract}
There exists a commonly held belief amongst musicologists that there has been a "general globalisation of styles" within recorded performances of the latter half of the twentieth century. For many, this is evidenced by an increased interaction between mainstream (MS) and historically informed performance (HIP) practices as well as a general decrease in the diversity of performances. Through a comparative aural and software-assisted analysis and measurement of performance features such as tempo, rhythmic flexibility, vibrato, portamento, bowing, and articulation in key interpretations of Bach's Suite No. 6 for Solo Cello recorded in between 1961 and 1998, this study investigates the relationship between MS and HIP performances in the latter half of the $20^{\text {th }}$ century. By limiting analyses to those performers who have made two recordings during the designated period (Tortelier, Starker, Bylsma, Ma, Wispelwey), it has been possible to identify overarching trends and individual differences. These have been examined with reference to their broader social and cultural context in order to test commonly held musicological assumptions about the modernist and postmodernist foundations of performances from this era. The results indicate that by the 1990s increased interaction between MS and HIP practices has resulted in a wider variety of differing performances and that this can be seen to be symptomatic of the postmodern condition that has become prevalent since the last decade of the $20^{\text {th }}$ century.
\end{abstract}

Submitted 2010 July 30; accepted 2011 April 14.

KEYWORDS: twentieth-century performance, cello suites, Bach, baroque performance

\section{INTRODUCTION}

THE landscape of musical performances over the course of the twentieth century has been the site of immense change. The steady growth of the recording industry has set new standards for performance and allowed music to be heard on demand and in a range of diverse settings. Concurrently, the rise of the Historically Informed Performance (hereafter HIP) movement has promoted the notion that works should be performed on "period" instruments and according to the perceived technical and stylistic conventions prevalent at the time of a work's composition. Together, these two forces have altered our culturally established perceptions of musicality and style. As the quality and quantity of recorded performances have surpassed by far the standards of the past, as the increasing popularity of HIP conventions have begun to seep into areas of mainstream (hereafter MS) performance, and as an increasingly perceptive listening public have craved new approaches to familiar pieces, a number of trends have been identified by musicologists which distinguish contemporary performances from those of the pre-1950s era.

Describing the latest trends that have emerged since the 1980s, Lawson and Stowell (1999, p. 160) have spoken of the "erosion" of the concept of early music "as period principles begin to be applied to mainstream situations." Ornoy (2006, p. 243) demonstrated "clear similarities" between HIP and MS 
performers' interpretative decisions and executions. Leech-Wilkinson (2009), along with many others (e.g. Day, 2000; Katz, 2004), has linked the technical accuracy and clarity that pervades most contemporary performances, whether MS or HIP, to the influence of the modern recording industry. Philip (2004, pp. 232-3), perhaps most succinctly and writing of the entire era of sound recordings, has spoken of an apparent "globalisation of styles" that has taken place as the influence of recordings has changed the way in which music is studied and assimilated. There is a shared perception that performances have tended to become more homogeneous in the post 1950 s era.

An alternative approach to performance studies that may seem, at least superficially, to support the view of assumed homogeneity in contemporary performances of Western music is found in empirical investigations conducted primarily in the domain of music psychology. Systematic examinations show that "artists are able to reliably repeat performances and normally do so, once a new piece has been prepared, giving essentially the same performance on more than one occasion" (Chaffin, Lemieux \& Chen, 2007, p. 455, referring to Shaffer, Clarke, \& Todd, 1985, among others). Although Chaffin and colleagues were investigating repeated performances within a very short time-frame, their results are relevant because they demonstrate the repeatability of performance. This has been corroborated by a recent study that compared live performances with studio recordings of the same artists in identical repertoire and showed verisimilitude across a difference of even several years (Fabian, 2008). Others have also shown that artists tend to establish their interpretations of a piece early in their career and rarely change it radically or recognizably (Leech-Wilkinson, 2010). If interpretations can be repeated and performers can put forward similar performances, then the notion of a homogenous performance style is plausible.

Some other empirical investigations focused on variations in performance that reflect deliberate changes in line with altered approaches to interpretation (Clarke, 1995; Repp, 1992; Spiro, Gold, \& Rink, 2010). Such fundamental re-interpretations have also been observed in recordings of first generation HIP players, for instance those of Leonhardt and Harnoncourt whose recordings from the 1950s do not show essential HIP characteristics. These appear only in their output from the second half of 1960s onwards, which include repeat recordings of several pieces (Fabian, 2003; 2006). In the MS field one of the best known case of change is Glenn Gould's two, at times radically different studio recordings of Bach's Goldberg Variations from 1955 and 1981, respectively (Bazzana, 1997; Fabian, 2006).

These performance trends can also be examined from the perspective of broader cultural developments. Among historical musicologists Taruskin was one of the first to call into question the historical validity of HIP and initiate a debate that would cast doubt over the legitimacy of claims fundamental to the HIP project (Taruskin, 1995). For Taruskin, HIP represents nothing more than a continuation of high modernist ideals. In his view, HIP has set about reducing the performer's creative input whilst increasing the strength of the musicologist's theoretical dicta. In his now infamous article, The Pastness of the Present and the Presence of the Past, Taruskin claimed that "historical performance today [i.e. the 1970s and 1980s] is not really historical; that a thin veneer of historicism clothes a performancestyle that is completely of our own time" (Taruskin in Kenyon, 1988, p. 152). Taruskin set his sights on the apparently depersonalised and technically precise style of playing that dominated performances, both MS and HIP, from the 1950s to the 1980s. For him, "a seismic shift in musical sensibilities" had occurred as academic musicologists, guided by logical positivism, showed an increased interest in performance studies. This seismic shift, according to Taruskin, resulted in a preference for the notated score over the performer's creative instincts and a playing style that was literal, geometric and dehumanising. Thus, for Taruskin, HIP is not historical at all but rather represents the conventional modernist predilection for the objectivity of the text over the subjectivity of the act. Whether one adheres to Taruskin's views or not, any discussion of performance practice, particularly one so focused on the performance of works from the Baroque period, cannot overlook the significance of these criticisms and their implications for understanding the changes in performance practice during the latter half of the $20^{\text {th }}$ century. From the ensuing debate has emerged a deeper understanding of the broader cultural movements that underpin approaches to performance.[1]

John Butt, who has written extensively and articulately on the topic, takes Taruskin's claims one step further by suggesting that HIP is "a phenomenon born of a typically modernist concern with the loss of one's historical and subjective depth, and one that is itself now a feature of a postmodern situation" (Butt, 2002, p. 144). For Butt, HIP is undoubtedly modern in its origins but has since evolved to reflect the changing perspectives of history and subjectivity in a postmodern world. Butt considers characteristic developments in HIP in relation to Lyotard's postmodernism. For the French philosopher, postmodernism was that which celebrated the plurality of ideas and opinions, the fragmentary nature of existence, dissension over consent, and the interaction of "little narratives" instead of the acceptance of grand, 
overarching systems of truth. Above all, the subject was to be defined by a constant play of "language games" in which differing discourses interrelated and cooperated to create new disciplines and modes of thought. History and tradition were no longer sufficient foundations on which to define existence (Lyotard, 1994). For Butt, post 1980 developments in HIP are a consequence of the postmodern existence in which historicity and subjectivity have been lost. Referring to the theories of Jameson (1991), Butt suggests that, "with the roots of historicity severed the historical urge returns in the form of a blind historicism" (Butt, 2002 , p. 160). Just as the Western world saw a rise in fundamentalism as tradition and history were threatened, so too, Butt argues, has musical performance witnessed the rise of a fundamentalist style of historically informed performance. Going further, Butt contends, this distinctly contemporary view of the past has brought with it new approaches to performance as HIP tendencies have become popularized and more widespread since the last decade of the twentieth century. As he states, "The historicist urge of HIP is perhaps 'authentic' for our times... and brings with it new intensities and resonances that are relevant for us in a way that would not have been available to the 'original' performers in history" (Butt, 2002, p. 163). HIP emerged from the modernist crisis of history but has since come to reflect the postmodernist preference for difference and plurality creating new discourses of musical performance as a result.

Dulak (1993) has also noted a relaxation of the HIP verbal discourse and the emergence of a more sumptuous and resonant style since the late 1980s, when younger performers started to embrace a more pluralistic world view. In the wake of Taruskin's criticism it became possible to admit to the impossibility of recreating the past exactly. With this, the individual performer's taste and musical temperament were allowed to come to the fore resulting in more varied interpretations. "As soon as it becomes acceptable to dislike what Bach might have done it is easier to allow [choices]. ... [H]istorical evidence can be treated critically, and one can acknowledge that there is no absolute distinction between the choice of personal insight - or opinion - and historical accuracy" (Butt, 1999, p. 191). Furthermore, recent record reviews and interviews testify to the notion that the HIP style has started to embrace the spirit rather than the letter of the eighteenth century: the emphasis has shifted from the rules of execution to the role of improvisation and the importance of being spontaneous (Taruskin, 2009a; Sherman, 1997).

To summarise, there exist a number of varied opinions on performance trends of the post-1950s era. Historically oriented views seem to share a common belief put forward most succinctly by Philip (2004) that holds responsible either the increasing influence of the recording industry or, at least in case of pre-1800 compositions, the rise in popularity of the HIP movement for a perceived lack of variety in the way in which music is now performed. Many believe that over the course of the last half-century there has emerged a homogeneity of performance styles that share a focus on technical proficiency over expressive diversity. It is this technical proficiency that the evidence of the more experimentally orientated studies from the music psychology domain supports.

However, there are also those who argue (or whose results imply) - whether on the basis of cultural investigations like Butt and Dulak or relying on experimental approaches like Clarke and Repp or on analysis of commercial recordings like Fabian, Leech-Wilkinson and Repp-that a new found expressive freedom and increased plurality of styles have emerged since the late 1980s. It is perhaps a far too recent development for the historically orientated studies to acknowledge this shift. There are also far fewer systematic studies of current performance trends than of earlier times. It remains to be seen whether enough empirical support can be shown to counteract the more popular view which laments the loss of individual difference.

\section{AIMS AND MATERIAL}

We are interested in how the individual artist responds and contributes to supposed performance trends. We intend to test the validity of claims put forward by historical musicologists regarding the presumed homogeneity and globalisation of performance styles on the one hand and an increased plurality since the late 1980 s on the other hand. Furthermore, we reflect upon broader cultural phenomena in the contemporary performance of Baroque music.

Through a close analysis of recorded performances of Bach's Sixth Suite (D Major) for Solo Cello (BWV 1012) over the period from 1961 to 1998, we intend to provide a detailed depiction of the changing landscape of performance since the 1950s focussing on distinguishing individual artistic attributes from more generally observable stylistic characteristics. The discussion of results engages with current debates over the modern and postmodern origins of HIP and the state of Baroque music performance today. More specifically, this paper has four aims: To examine (1) the changes in performance practices of Bach's Sixth 
Cello Suite in the latter half of the $20^{\text {th }}$ century; (2) the relationship of MS performance to HIP and the perceived emergence of shared performance characteristics; (3) the development of individual profiles over time and the potential impact of trends on them, and (4) the effects of broader social/cultural trends on performances and individual performers from this period.

\section{Choice of repertoire}

The area of recorded performance analysis has been growing steadily since the 1990s. Several historical musicologists have conducted detailed studies of commercially recorded performances using a range of differing works as the basis for their analyses (for instance Bowen, 1996; Butt, 1999; Fabian, 2003; 2005; Fabian \& Ornoy, 2009; Leech-Wilkinson, 2006; 2009; Milsom, 2003; Ornoy, 2006; 2008; Philip, 1992; 2004). As yet however, there has been no thorough examination of recorded performances of Bach's Six Suites for Solo Cello (apart from brief overviews within record reviews such as Taruskin (2009b) and a study of the Sarabande from the C Major Suite (Hong, 2003)). Given the fact that the performance history of the suites has developed in close proximity to the development of the recording industry this is surprising.

Bach's cello suites have held a position of immense significance within the cello repertoire since their "re-discovery" by Pablo Casals. Additionally, they are also appreciated by many classical and nonclassical listeners. Through their use in film, advertising and other popular forms of media, they have achieved a degree of widespread recognition not usually granted for works from within the classical canon. As a result, there currently exist over 50 recordings of the suites (Siblin, 2009, p. 6) with more being added each year. They reflect the changing nature of recorded performance styles and therefore make them an ideal candidate for the present study.

In addition to this, the fact that the suites were composed during the Baroque era has made them the focus of many HIP recordings. Questions of period instrumentation and articulation, historical tuning, and Baroque technique are regularly applied to any performance of the works. That the Sixth Suite was written for an unspecified five-stringed instrument makes it especially interesting for performers of the HIP style (Siblin, 2009, p. 225), although none of the selected recordings seem to use such an instrument. Their status as staples of both the HIP and MS cello repertoire enables a comprehensive examination of changing performance styles within the designated time period.

Finally, that the works currently have no autograph copy of the score further emphasises their significance for this study. The exact specifications of the composer can only be guessed at through study of four differing copies of the original text (Winold, 2007, p. 9). As a consequence, these works have remained significantly more open to interpretation than others by Bach. If a gradual "homogeneity" in performances of the cello suites can be perceived, then this should provide strong evidence for the validity of the claims mentioned at the outset.

\section{METHOD}

The performance of music is guided by a complex decision making process. As Leech-Wilkinson (2009), Philip (1992), and Chaffin, Imreh, and Crawford (2002) among others have shown, recorded performances represent the culmination of many decisions made by the performer. Yet any detailed empirical study of recorded performances will inevitably face the problem of distinguishing decisions that are guided by the performer's own unique stylistic concerns from those that are guided by the general trends of their historical, geographical or stylistic context. As Bowen (1996, p. 20) articulates, "it is altogether too easy to mistake a performance characteristic for a unique interpretive feature when it is, in fact, a general style trait of an unfamiliar style."

Our research addressed this problem by selecting for comparison only those performers who had made two recordings of Bach's Sixth Suite in the designated period. By identifying the constant elements of their performances, it was possible to go some way in distinguishing those characteristics that seemed unique to each performer and those that might have been guided by external stylistic and historical trends. The recordings examined were (see Discography for details): Paul Tortelier (1961; 1982), János Starker (1963; 1992), Anner Bylsma (period apparatus [HIP] 1979; 1992), Yo-Yo Ma (1983; 1995), and Pieter Wispelwey (period apparatus [HIP] 1990; 1998).

In our survey of the work's discography we found no other cellists who had made two recordings of Suite No. 6 during the designated post 1950s period. The Bylsma and Wispelwey recordings were 
identified as HIP because of the period apparatus used and because both players are strongly associated with the HIP movement. As Campbell observes, Bylsma's "re-interpretation of the earlier cello repertoire is probably his most notable and lasting achievement" (Campbell, 1988, p. 291). Similarly, Wispelwey's recordings are, without fail, consistently discussed in relation to notions of "authenticity" and "historical accuracy." Their HIP status was tested through analyses of performance characteristics and is discussed in the results section.

Of the remaining performers studied, Tortelier remains unquestionably in the MS camp. Identifying objectivity and emotional detachment as synonymous with the idea of authenticity, Tortelier distinguished himself by maintaining a firm belief in the importance of subjectivity and individual style. $\mathrm{He}$ states, "Over the last decades there has been a tendency towards 'authenticity', towards 'respect'. ...Well, some people can be blinded by respect. ... We mustn't be too afraid of making the music ours" (Tortelier, 1984, pp. 152-3).

Starker, like Tortelier, is another cellist who can clearly be identified as MS. Described as "the pre-eminent modern-instrument exponent of the Bach Suites" (Gramophone, August 1999, p. 39), he has become well-known for his technical mastery when performing all works in the cello repertoire, regardless of their historical origins.

Ma, the youngest of the MS cellists, has come to be recognised as one of the leading performers of both classical and non-classical cello music. Despite his obvious awareness of HIP performance conventions, Ma's approach to the Bach suites is one which "leans towards the approach of the traditional virtuoso cello school" (Gramophone, June 1984, p. 55) and clearly delineates him from his HIP peers.

Analysis for this study was carried out in stages. In all stages, both authors examined the recordings. Although the recordings were not analysed blind, the authors have different musical backgrounds and experiences (e.g. the first author is a cellist whereas the second author is a researcher of twentieth-century Baroque performance practice). They analyzed the recordings independently and over an extended period of time to counteract possible listener bias. In the first stage, all movements from all performances were listened to repeatedly in order to complete a spreadsheet detailing tempo, rhythmic flexibility, bowing and articulation, vibrato, and portamento. In addition, distinctive technical observations and general remarks were made to record an overall impression of each performance.

In the second stage, more focused analysis could be carried out through the use of Sonic Visualiser, a software program designed for viewing and analysing audio files.[2] Average beat per minute (bpm) tempo was calculated from overall durations, taking into account the number of bars and time signature and discounting final ritards and pauses. To quantify rhythmic flexibility, note onsets were first marked on spectrograms of the audio samples. Accuracy was checked aurally. This data was then transferred to a spreadsheet (MS Excel) in order to calculate the length of each note (inter-onset-interval, or IOI) within the sample. In the Allemande each note onset of the opening bar was recorded in all studied performances, the data normalized and compared graphically. In the Prelude, the measured durations were compared to a nominal projected pulse (which was derived from the performer's average tempo) in order to examine how far the performer deviated from the tempo. In all samples each beat of the first twelve bars was measured to ensure recognizable differences between players. The Prelude of the Sixth Suite consists of even eighth-notes throughout, notated in 12/8. Given the customary tempo and harmonic rhythm of the Prelude, measuring deviation from a nominal pulse makes more sense at the beat level than any smaller or larger unit.

For measuring vibrato speed and depth the software Spectrogram 14 was used.[3] It provides spectrographic visualization of the audio data in an easy to read and study manner. [4] Vibrato speed was calculated by counting the number of cycles within a given time-frame, dividing it by the duration in milliseconds and then multiplying by 1000 . Fifteen notes were selected for examination from the Allemande and Sarabande movements. The notes were selected on the basis of their duration and musical context that made them likely to be played with vibrato and suitable for reliable vibrato measurement. The same notes were also used to measure vibrato depth/width. This was calculated from frequency differences between the lower and upper edges of vibrato curves through careful inspection of the spectrographic display. The spectrogram and window size were set to the following parameters: High band Hz: 3200; Display width: $8 \mathrm{sec}$; Frequency resolution: $9.4 \mathrm{~Hz}$. Colour scales: maximum band: -80dB, minimum: $10 \mathrm{~dB}$. Vibrato depth in linear fraction of semitone (sT) was calculated using the following equation:

Vibrato width $\mathrm{sT}=$

$\frac{2^{*} d}{\left(0.059^{*}(1+h)\right)}$


where $\mathrm{d}=$ difference in $\mathrm{Hz}, \mathrm{l}=$ lower and $\mathrm{h}=$ higher measured $\mathrm{Hz}$. The number 0.059 takes care of the variation in $\mathrm{Hz}$ differences depending on which partial (harmonic) the researcher selects for measurement. Generally higher partials make vibrato measurement easier because there is a greater difference in $\mathrm{Hz}$ (i.e. the vibrato curves are larger).[5]

Observations gathered from stage one of analysis informed which movements and sections to focus on and which techniques to examine. Data collected from stage two, which specifically detailed vibrato, tempo, and rhythmic flexibility, was used to support the general impressions gained during stage one.

In stage three, the data was examined from several different perspectives. In order to respond to the main aims, each performer's first recording was compared to their second recording so that a profile of each performer could be made. In addition, all performances were compared to each other in chronological order so as to identify the existence of broad trends from the period.

\section{RESULTS AND DISCUSSION}

\section{Changes in performance practices}

\section{TEMPO}

Average measured tempi are summarized in Table 1. These are discussed in the context of the general claim by music critics that performances have become faster over time, especially HIP versions (Philip 2003; Taruskin, 1988)

Table 1. Average tempi (in bpm) of movements in the 10 recordings, listed in pair-wise chronological order. The tempo of the Gavotte movement reflects an average across the two Gavottes and the return of Gavotte I. Fastest versions of each movement are marked with asterisk.

\begin{tabular}{|l|l|l|l|l|l|l|}
\hline Performer & $\begin{array}{l}\text { Prelude } \\
\text { (dotted } \\
\text { quarter) }\end{array}$ & $\begin{array}{l}\text { Allemande } \\
\text { (quarter } \\
\text { note) }\end{array}$ & $\begin{array}{l}\text { Courante } \\
\text { (quarter } \\
\text { note) }\end{array}$ & $\begin{array}{l}\text { Sarabande } \\
\text { (half note) }\end{array}$ & $\begin{array}{l}\text { Gavotte } \\
\text { (quarter } \\
\text { note) }\end{array}$ & $\begin{array}{l}\text { Gigue } \\
\text { (dotted } \\
\text { quarter) }\end{array}$ \\
\hline Tortelier 1961 [MS] & 80 & 19 & 119 & 42 & 145 & 72 \\
\hline Tortelier 1982 [MS] & 75 & 17 & 126 & 35 & 141 & $77^{*}$ \\
\hline Starker 1963 [MS] & 90 & 21 & 120 & 36 & 150 & 75 \\
\hline Starker 1992 [MS] & 80 & 18 & 114 & 40 & 132 & 67 \\
\hline Bylsma 1979 [HIP] & 91 & $23^{*}$ & 123 & $48^{*}$ & $157^{*}$ & $77^{*}$ \\
\hline Bylsma 1992 [HIP] & 95 & 19 & $121^{*}$ & 46 & 124 & 74 \\
\hline Ma 1983 [MS] & $102^{*}$ & $23^{*}$ & 120 & 44 & 154 & 72 \\
\hline Ma 1995 [MS] & 93 & 20 & 111 & 37 & 146 & $77^{*}$ \\
\hline Wispelwey 1990 [HIP] & 88 & 21 & 111 & 37 & 126 & 68 \\
\hline Wispelwey 1998 [HIP] & 88 & 19 & $121^{*}$ & 33 & 129 & 69 \\
\hline Average Tempo & 88 & 20 & 119 & 39 & 140 & 72 \\
\hline Average Tempo to 1983 & 84 & 19 & 122 & 38 & 145 & 74 \\
\hline Average Tempo post '83 & 89 & 19 & 114 & 39 & 131 & 70 \\
\hline
\end{tabular}

General trends with regard to tempo choices are difficult to summarise when MS and HIP performers are examined together. Most notable in pairs of recordings is a tendency to play slower in the later version. The main exceptions to this are Tortelier and Wispelwey's Courantes and the Gigue which slows in Starker and Bylsma's respective recordings but speeds up in the others. In the Prelude, there is a very minor overall tendency to speed up from Tortelier's first recording to Wispelwey's in 1998. However, the sample size is small and trend lines are not strong (as indicated by examined $\mathrm{R}^{2}$ values that were all low).[6] Therefore it is useful to examine the percent differences between earliest and latest recordings as well as between fastest and slowest (Table 2). These provide a more refined picture and can be evaluated in light of research on perception of tempo difference (Levitin \& Cook, 1996; Sheldon \& Gregory, 1997). The data show a 10\% increase of tempo in the Prelude and an $11 \%$ decrease of speed in the Gavotte between the earliest and 
latest studied recordings. Hardly any tempo differences are observed in the other movements. When the fastest and slowest versions are compared, the percent differences are considerably greater. Depending on tempo, a variation of more than $8 \%$ tends to be noticed by even inexperienced listeners (Levitin \& Cook, 1996).

In terms of chronology, a peak of tempi occurs around the beginning of the 1980s, with Bylsma's HIP version often in lead position. As the calculation of averages before and after 1983 also indicates (last two rows in Table 1), the gradual decrease of tempi is from this point rather than from the beginning of the examined period. The result seems to fit in well with other reported tempo trends in Bach repertoire (Fabian 2003; 2005). However, the more general claim of tempi becoming ever faster (e.g. Taruskin, 1995) needs to be qualified by nominating the mid 1980s as potentially the end of this trend. The easing of tempi since the late 1980s may also be indicative of a more expressive style that is less concerned with technical brilliance and literal delivery than with inflecting and shaping the music; nuances that are harder to achieve at extreme fast tempi.

Table 2. Global tempo differences between recordings, expressed in percentage. A negative number indicates slowing of tempo; positive number indicates speeding up.

\begin{tabular}{|l|l|l|l|l|l|l|}
\hline \% Difference between & Prelude & Allemande & Courante & Sarabande & Gavotte & Gigue \\
\hline First and last recording & 10 & 0.5 & 0.2 & -0.7 & -11 & 0.3 \\
\hline Fastest and slowest rec. & -26 & -26 & -11 & -33 & -21 & -13 \\
\hline
\end{tabular}

\section{RHYTHMIC FLEXIBILITY}

Earlier performances tend to have a more literal approach to rhythm, especially in the Prelude, but in the Courante, Gavotte and Gigue as well. In most movements of all earlier versions rubato is generally restricted to phrase ends demarcating major structural units. The extent to which it appears is moderate and at times seems only to underscore the delivery of dynamics or chords (e.g. Starker, Bylsma). In the Courante it is used to delineate counterpoint and repeated melodic figures (e.g. Tortelier), or sixteenth-note runs from ensuing eighth notes (e.g. Starker).

By the early 1990s this trend has been reversed and performers appear to stress the importance of melodic and harmonic material over rhythmic precision. In the faster movements, a strict continuity of beat is often diminished and more emphasis is placed on attempting to highlight smaller rhythmic units. In the slower movements, more time is spent on the rhythmically and harmonically strong beats while the intervening melodic material is treated as secondary. Rubato is not only more prevalent (except in the Gavotte and Sarabande movements) but often a key means of shaping and structuring the music. In these later recordings rubato tends to be localised, affecting the timing and grouping of notes rather than tempo.

Aspects of rhythmic flexibility were quantified by measuring note durations in the Prelude (which moves by even eighth-notes) and by plotting the results against a nominal projected pulse. The results supported the overall impression and are illustrated in Figures 1-2 which contrast Starker's two MS recordings with Bylsma's HIP versions (see also Figure 4 under Bylsma and Figure 5 under Wiespelwey in Section 3 below). While Bylsma's HIP recording shows less overall rhythmic flexibility than Starker's MS recordings, a clear increase in rhythmic flexibility can nevertheless be observed in Bylsma's later version as well. 


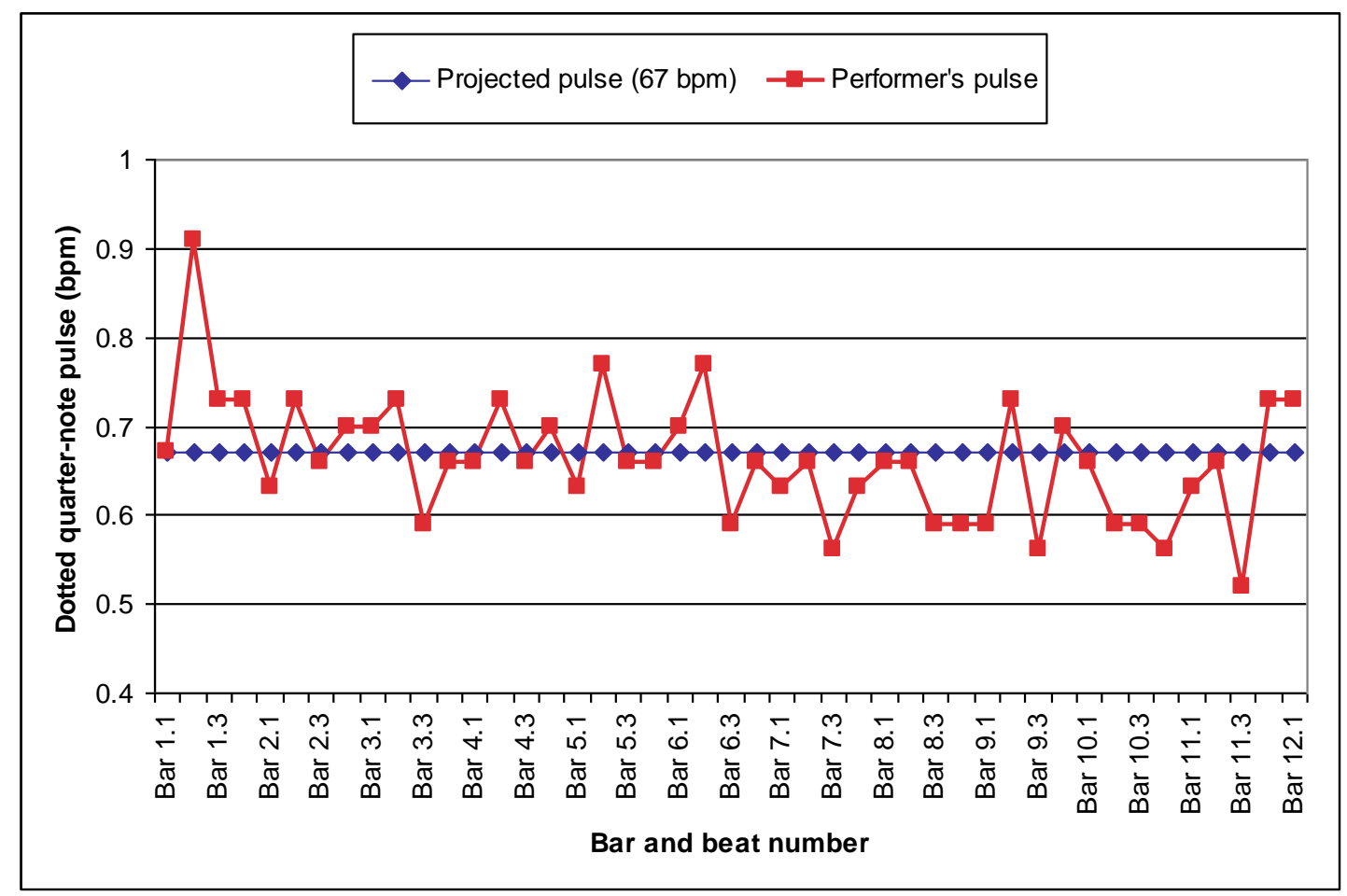

Figure 1a. Starker 1963 [MS]: Rhythmic Flexibility in Prelude b. 1-12. Nominal projected pulse (bpm) plotted against actual delivery.

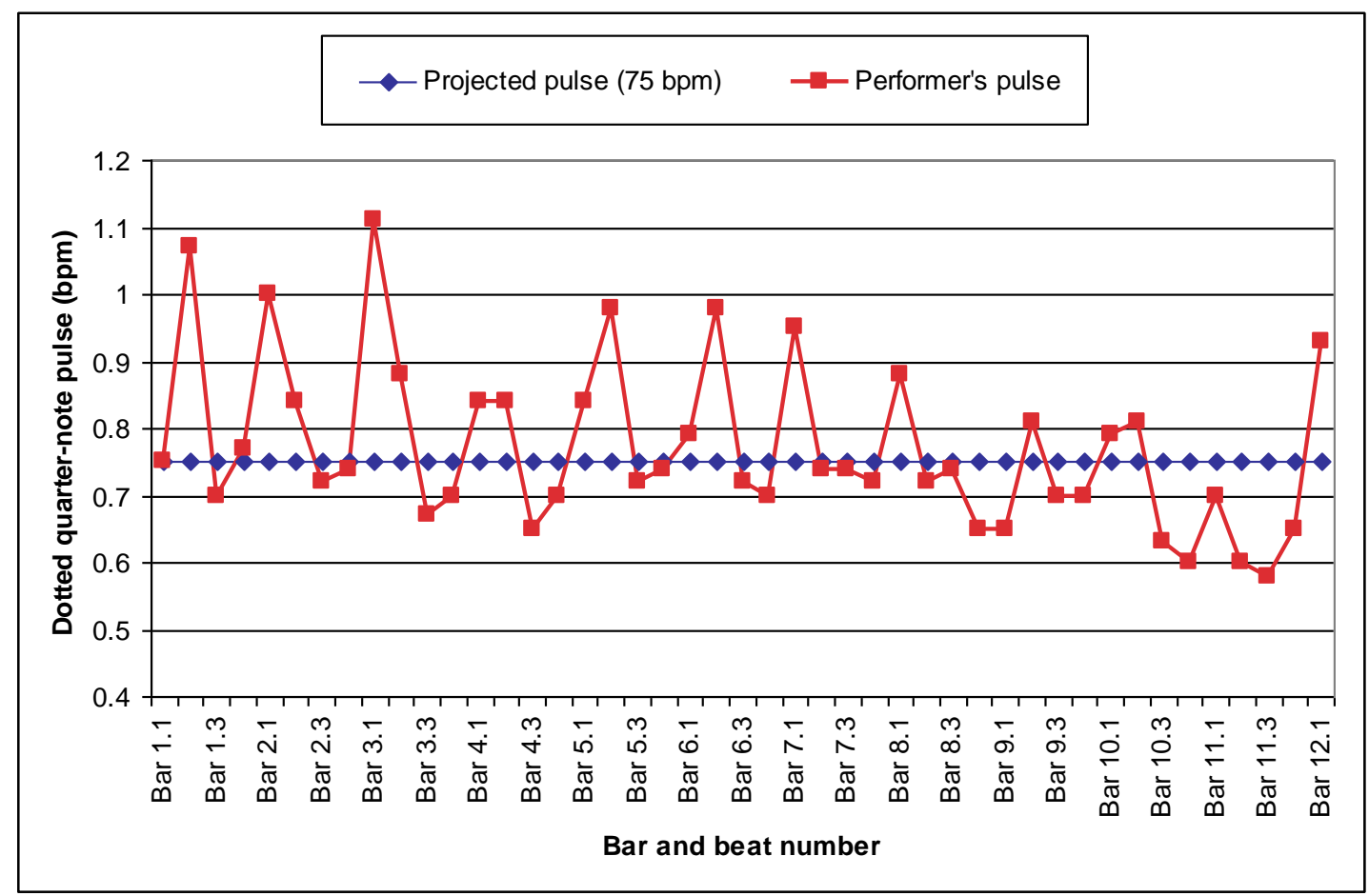

Figure 1b. Starker 1992 [MS]: Rhythmic Flexibility in Prelude bars 1-12. Nominal projected pulse plotted against actual delivery showing a dramatic increase in deviation compared to Figure 1a. 


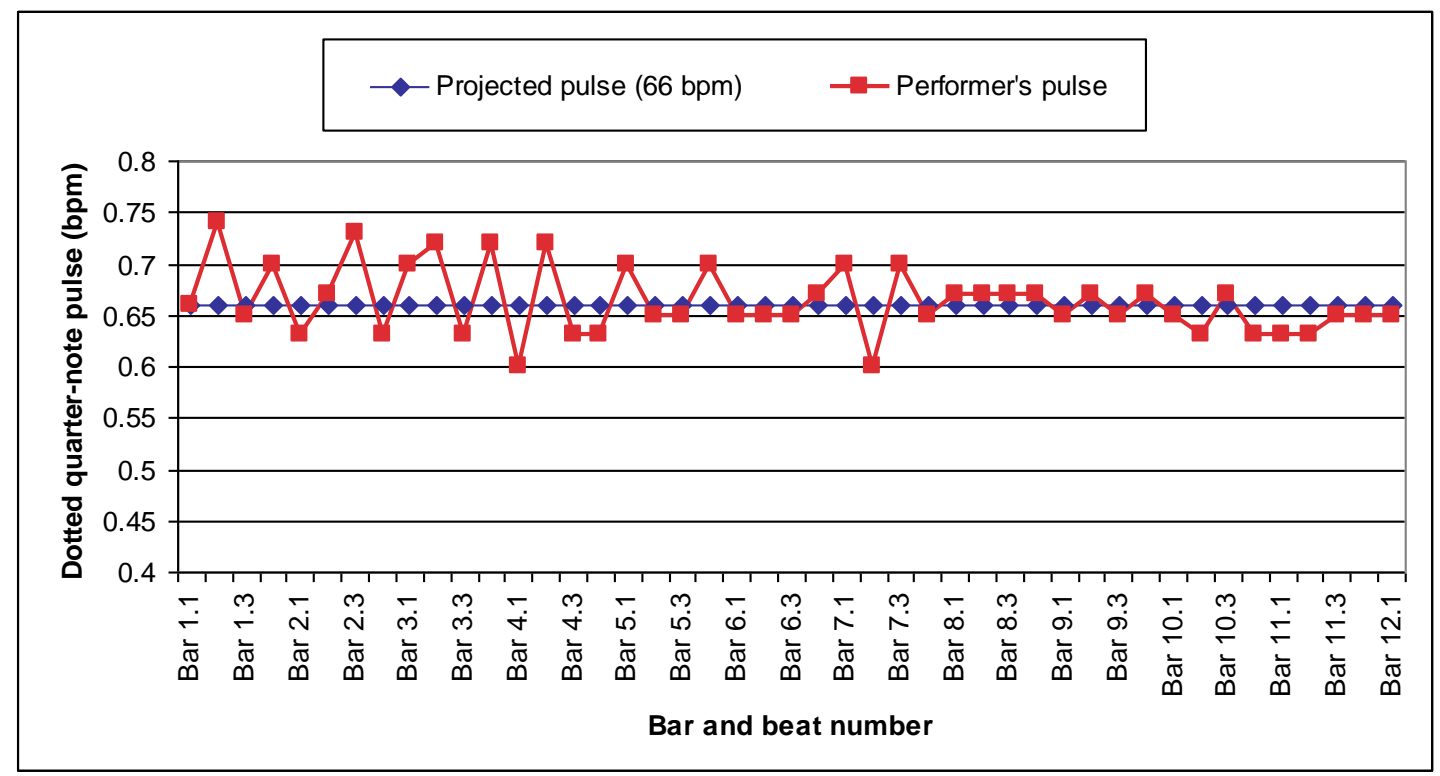

Figure 2a. Bylsma 1979 [HIP]: Rhythmic Flexibility in Prelude bars 1-12. Nominal projected pulse plotted against actual delivery

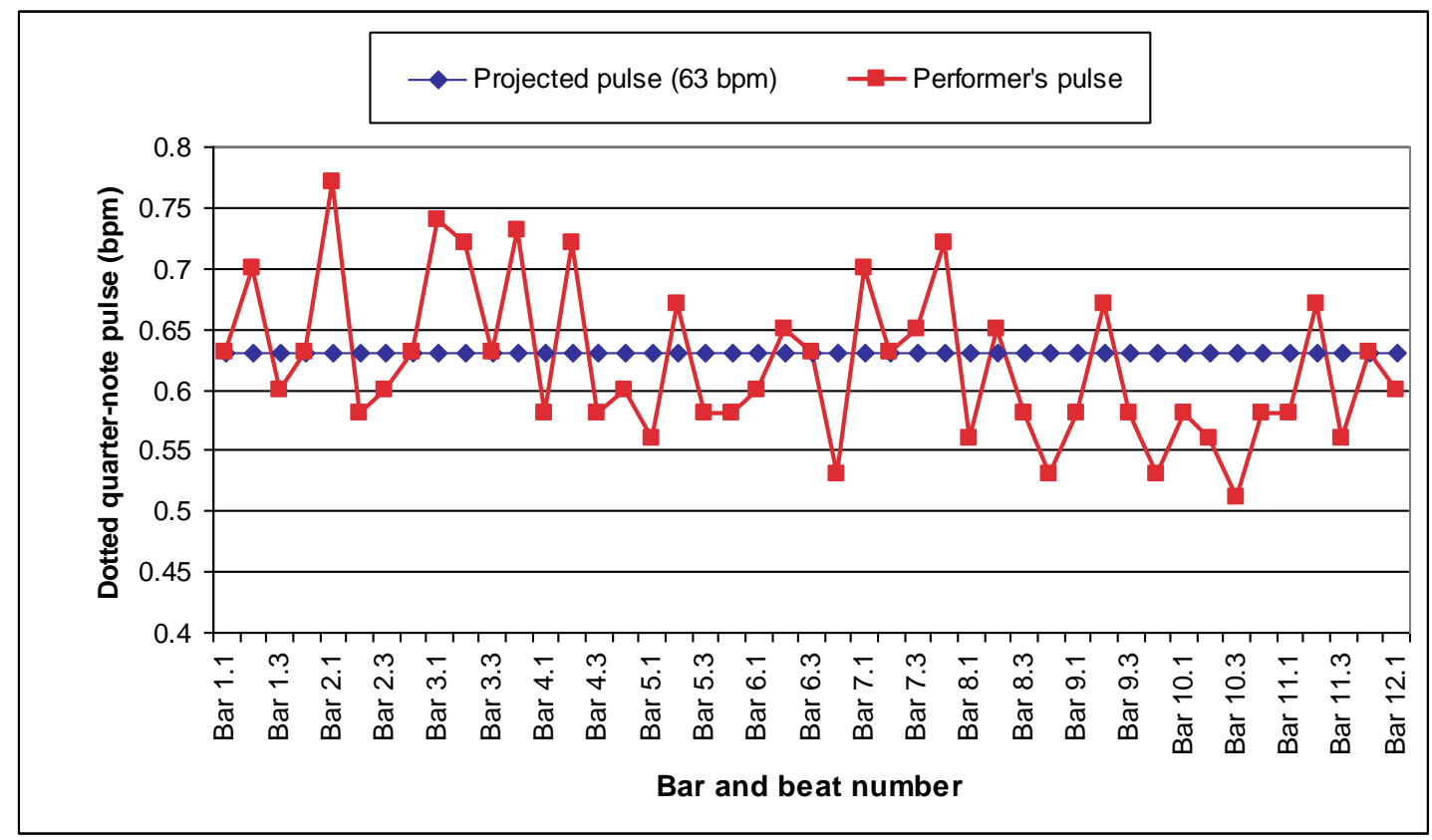

Figure 2b. Bylsma 1992 [HIP]: Rhythmic Flexibility in Prelude bars 1-12. Nominal projected pulse plotted against actual delivery showing a dramatic increase in deviation compared to Figure 2a. 


\section{BOWING AND ARTICULATION}

Bowing and articulation were analysed aurally. Although both varied from movement to movement, overall it could be said that MS performers tended to maintain a legato bow stroke with a consistent bow pressure until the 1990s when they began to use a lighter, slightly shorter stroke and allowed for more silence between phrases. This is particularly noticeable in Ma's 1995 performance of the suite and in Starker's 1992 interpretation of the slower Allemande and Sarabande movements. By contrast, performers in the HIP tradition maintained a short and clearly articulated bow stroke throughout the fast movements and a light stroke with greater variety of tone in the slower movements. Generally, they made use of silence and allowed notes to decay more noticeably than MS players. Given that short, clearly articulated bow strokes are among the most important staples of the HIP style established by the end of the 1970s and enabled by the shorter period bow, it is not surprising that HIP players show less change in their approach to bowing and articulation.

While bowing and articulation seem to vary less in HIP performances, there is a noticeable change that occurs in the execution of chords across both performance styles. In MS as in HIP performances from the 1960s to the 1990s, chords move from being executed in rhythmically efficient blocks to being rolled, or divided into two halves. Most obvious in the Gavotte, this change is achieved primarily through a progression from a fast, weighted stroke to a slower, lighter and less accented stroke. While performances from the 1960s to the 1980s tend to favour the heavier, faster stroke, by the 1990s, all performers are using a softer stroke and breaking the chords into multiple parts in accordance with HIP theory that advocates arpeggiation of multiple stops based on information found in eighteenth-century treatises (Donington, 1989, p. 543; Boyden, 1965, pp. 436-443, both quoting Rameau's "Preface" to the Paris 1741 publication of his Pièces de clavecin en concerts, among others). As a result, these performances show a reduced sense of rhythmic continuity which supports the changes occurring in rhythmic flexibility.

\section{VIBRATO}

The results of vibrato measurements are summarized in Table 3. Aural analyses and visual examination of spectrograms showed differences in the frequency of vibrato use between MS and HIP styles. According to generally accepted HIP conventions, vibrato is to be suspended "on all but the most special notes, where it is an ornament" (Laird, 2004, p. 329). Not surprisingly, this study found that MS performers show a more frequent use of vibrato than their HIP counterparts. Even so, this HIP principle seems to have influenced MS players, as most of them reduce the occurrence and width of vibrato in their later recordings. The extent to which they do so is varied. In general, MS performers use a wider vibrato than those working in the HIP style.

Table 3. Average vibrato speed and depth in pair-wise chronological order of the 10 recordings, measured on 15 longer notes selected from the Allemande and Sarabande movements

\begin{tabular}{|l|l|l|}
\hline Performer & $\begin{array}{l}\text { Average vibrato speed in cycles per } \\
\text { second (cps) }\end{array}$ & $\begin{array}{l}\text { Average vibrato depth in } \\
\text { fraction of semi-tone (sT) }\end{array}$ \\
\hline Tortelier 1961 [MS] & 6.34 & 0.26 \\
\hline Tortelier 1983 [MS] & 6.38 & 0.22 \\
\hline Starker 1963 [MS] & 7.09 & 0.16 \\
\hline Starker 1992 [MS] & 6.49 & 0.26 \\
\hline Bylsma 1979 [HIP] & 6.15 & 0.12 \\
\hline Bylsma 1992 [HIP] & 6.03 & 0.1 \\
\hline Ma 1983 [MS] & 5.84 & 0.12 \\
\hline Ma 1995 [MS] & 5.85 & 0.15 \\
\hline Wispelwey 1990 [HIP] & 5.84 & 0.08 \\
\hline Wispelwey 1998 [HIP] & 5.99 & 0.07 \\
\hline
\end{tabular}




\section{PORTAMENTO}

Shifting from one position to another on a string instrument can be executed silently or with an audible slide that is often referred to as portamento, a term borrowed from vocal techniques. Modern aesthetic sensibility favours silent shifting but expressive slides (i.e. portamento) were commonly used until the 1930 s by both violinists and cellists. It is widely held that the increased reliance on vibrato since the beginning of the $20^{\text {th }}$ century, together with a rejection of subjective emotionality gradually curtailed the use of expressive portamenti completely (e.g. Katz, 2004; 2006). Our data set confirms this development. Shifting tended to be executed silently with few expressive slides observable, mostly in the earlier MS recordings, especially in Starker's.

\section{Relationship of MS performance to HIP}

From the observations above, there is a lot to suggest that the HIP style had a major influence on MS performers. This is not surprising when one considers that works of the Baroque period were the first to be targeted by HIP enthusiasts and have therefore played a major part in forging the HIP aesthetic. The extent to which the HIP movement influenced MS performers becomes increasingly obvious when specific technical elements are examined.

Despite the plurality within HIP practices throughout the examined period from 1961 to 1998, HIP players tend to maintain a shorter bow stroke with clear articulation and greater use of silence between bow strokes. While this is no doubt closely related to the use of period instruments (e.g. shorter Baroque bows), there is an increasing use of a shorter, lighter bow stroke in MS performances as well by the beginning of the 1990s. With this, there is also an increasing use of silence between bow changes and a stronger projection of rhythm and pulse that appear in MS performances from around this time, making comparisons to the HIP style unavoidable.

Another obvious comparison can be made with regard to the use of vibrato. HIP players consistently refrain from using excessive amounts of wide vibrato. While early MS performances generally make use of a wide and near continuous vibrato, by the early 1990s most MS performers have reduced the width of vibrato since their first recording. There appears to be a widespread adoption of HIP conventions even if moderated to suite modern instruments.

When comparing tempo choices of players, the decrease of tempo between first and second recording is found to be typical in most movements. Although the sample size is very small, there is a mild tendency for HIP performers to choose slower performance tempi than their MS counterparts. This might be surprising given the general criticism of HIP players" "breathless" tempo choices (e.g. Taruskin, 1995). It is possible that such criticism is responding to performances up to the mid-1980s, where a peak of tempo choices is observed in our data set as well. Furthermore, the fact that MS performers have not slowed as noticeably as HIP versions could be indicative of a lag in influence: the fast HIP tempi of the late 1970s and early 1980s might still be the "model" for MS players when interpreting Baroque repertoire. Meanwhile the HIP style has evolved to allow for greater expressivity and flexibility which requires more time for delivery and thus fosters a slowing of tempo as witnessed here and argued by others (Dulak, 1993; Fabian, 2003; Haynes, 2007). The correlation between slower tempo and increased relative variation in expressive timing has been established by Repp (1995) both in performance and the aesthetic judgement of it.

Interestingly, as the two styles progress, they share a common rejection of literalist approaches to rhythm that dominated earlier performances. From the 1990s, both MS and HIP players show increased levels of rhythmic flexibility. While MS players tend to use more rubato and rhythmic flexibility in general, there is a clear increase of localized rhythmic flexibility in HIP recordings. It is particularly noteworthy that the two HIP versions of the Allemande use rhythmic flexibility to treat smaller notes as ornaments. In contrast, the rubato of MS players, even that of Ma, tends to be guided by phrasing and highlights longer units and melodic lines. This difference in the kind of flexibility displayed by HIP versus MS performers remains a key distinguishing factor between the two styles and underscores the alternative foundation of HIP expressivity. For HIP performers, expressivity is embedded in articulation that projects the pulse of the music and highlights metrical hierarchies while being closely linked to minute harmonic movements. By contrast, expressivity for MS performers tends to be melodically conceived and oriented. Although both MS and HIP players move away from the literal style of playing apparent in earlier performances, they do it 
in differing ways. Flexibility in MS versions is primarily observed in terms of phrasing; in HIP it is more locally nuanced creating an "inflected" style.

\section{Performer profiles and comparisons of earlier and later recordings}

The most noticeable individual characteristics as well as features reflecting trends are summarized in Table 4. The most striking features of each cellist's respective recordings are listed in chronological order of birth and recording date and are expanded below.

Table 4. Consistencies and Relevant Changes from first to second recording of each selected cellist.

\begin{tabular}{|c|c|c|}
\hline Performer & $\begin{array}{l}\text { Consistencies across earlier } \\
\text { and later recording }\end{array}$ & $\begin{array}{l}\text { Relevant changes from earlier to later } \\
\text { recording }\end{array}$ \\
\hline $\begin{array}{l}\text { Tortelier } \\
\text { (b.1914) }\end{array}$ & •Full, weighted bow stroke & $\begin{array}{l}\text { - Changes in tempo } \\
\text { •Increased rhythmic flexibility }\end{array}$ \\
\hline $\begin{array}{l}\text { Starker } \\
\text { (b.1924) }\end{array}$ & $\begin{array}{l}\text {-Prominent use of vibrato } \\
\text {-Deliberate shifting }\end{array}$ & $\begin{array}{l}\text { - Changes in tempo } \\
\text {-Increased rhythmic flexibility } \\
\text { - Altered vibrato speed and width } \\
\text { - Altered bow stroke }\end{array}$ \\
\hline $\begin{array}{l}\text { Bylsma } \\
\text { (b.1934) }\end{array}$ & $\begin{array}{l}\text { - Limited use of vibrato } \\
\text {-Silent shifting } \\
\text { - Tone quality }\end{array}$ & $\begin{array}{l}\text { - Changes in tempo } \\
\text {-Increased rhythmic flexibility } \\
\text {-Altered bow stroke }\end{array}$ \\
\hline $\begin{array}{l}\text { Ma } \\
\text { (b.1955) }\end{array}$ & -Vibrato speed and width & $\begin{array}{l}\text { - Changes in tempo } \\
\text {-Increased rhythmic flexibility } \\
\text { - Altered bow hold } \\
\text { - Use of Baroque tuning }\end{array}$ \\
\hline $\begin{array}{l}\text { Wispelwey } \\
\text { (b.1965) }\end{array}$ & $\begin{array}{l}\text {-Limited use of vibrato } \\
\text {-Silent shifting } \\
\text {-Tempi }\end{array}$ & $\begin{array}{l}\text { - Slight increase in rhythmic flexibility } \\
\text { - Altered bow stroke }\end{array}$ \\
\hline
\end{tabular}

\section{PAUL TORTELIER (1914-1990)}

Aural analysis of Tortelier's two performances from 1961 and 1983 revealed the use of a generally full, weighted and consistent bow stroke as well as a relatively moderate or "steady"[7] vibrato speed (6.3 and 6.4 cycles per second respectively). This has a significant effect on the overall timbre of each performance, making them sound extremely similar and reflecting the literal, even, technically perfect, well-projected MS playing of the 1950s-1980s (audio sample 1).

Nevertheless, in the later 1983 recording there appears to be an attempt to exaggerate the character of each movement. This is achieved primarily through the broadening of tempi, through an increase in rhythmic flexibility, or a combination of both. With the exception of the Prelude, the faster movements are generally faster while the slower movements display a markedly slower tempo (cf. Table 1 above) allowing for more rhythmic flexibility and the exaggerating of melodic ideas. This in turn assists in emphasising the general character of each movement. Although in absolute numbers the tempo range seems wider in the fast movements, when the difference is expressed in percentages it transpires that the tempo of the Allemande and the Sarabande, the two slow movements have changed the most (11\% and $17 \%$ respectively). As the perceptual threshold for tempo similarities is about 8\% (Levitin \& Cook, 1996), these differences in Tortelier's two readings are easily noticeable. Furthermore, "listeners tend to perceive slower tempi more readily and accurately than ... tempos that accelerate" (Sheldon \& Gregory, 1997, p. 376).

Overall, it could be said that both of Tortelier's performances are fundamentally very similar and reflective of MS aesthetics that were fashionable during the middle of the $20^{\text {th }}$ century. Changes to his later 1983 interpretation are found in small-scale rhythmic details and in the broadening of tempi. 


\section{JÁNOS STARKER (1924 - )}

Like Tortelier, Starker maintains a number of distinct characteristics throughout both the 1963 and 1992 performances. Most noticeable is the continuous use of vibrato in the majority of all movements. While crucial aspects of the vibrato undergo important changes, its presence throughout both performances is clearly audible. As well as this, he maintains a particularly deliberate approach to shifting throughout: fast movements make use of clean shifting, while slow movements make use of more audible and expressive shifting (portamento). Again, these features, although seemingly idiosyncratic, fit in well with general descriptions of the MS style from mid-century and make both recordings seem extremely similar.

Despite this, there is evidence to suggest a broad attempt to relax the overall mood of the later 1992 performance through the use of slower tempi, increased rhythmic flexibility and a traceable change in the type of vibrato used. In the 1992 recording, all movements, except the Sarabande, show a decrease in tempo (cf. Table 1 earlier) which results in less rhythmic drive. In terms of percentages the tempo of the Sarabande has increased by $11 \%$ while the Allemande has slowed by $14 \%$, the Gavotte by $12 \%$, the Prelude and Gigue by $11 \%$, but the Courante only by $5 \%$. As a consequence of the more leisurely tempo, Starker generally takes more time between bars and phrases displaying increased rhythmic flexibility. With this, in the Gavotte and Gigue, chords move from being played in efficiently swept blocks to being played in two separate halves. This has the effect of further disrupting the stability of the beat.

Most notable however, is the change in vibrato speed and width. In his earlier 1963 recording Starker's vibrato is fast and narrow. The effect of this is an extremely intense or concentrated vibrato sound. By contrast, in his later 1992 recording there is an obvious slowing of the vibrato speed while the width of the vibrato is clearly extended (cf. Table 3 above). As a result, the vibrato sounds looser and more relaxed. The difference in vibrato width is not only considerable in comparison with measured changes in the other recordings but also against the trend.

There is also a change in bow stroke. Where Starker's 1963 performance makes use of a predominantly even, continuous and legato stroke, the later 1992 performance shows a small but perceptible shift towards allowing notes to decay. In the Sarabande and, to a lesser extent, the Prelude and Allemande, notes are less sustained and often allowed to ring out to silence (audio sample 2). The effect of this is increased time between melodic ideas and increased awareness of accenting and the attack of specific notes.

In general, it seems that Starker maintains a continuous use of vibrato and a measured approach to shifting, both typical characteristics of MS practice. However, as a result of his using predominantly slower tempi, allowing increased flexibility, and varying his vibrato speed and width, it appears that Starker aims to present a looser, more relaxed and less literal performance in his later 1992 recording.

\section{ANNER BYLSMA (1934 - )}

As might be expected, both of Bylsma's performances display technical elements fundamental to the HIP style. He uses vibrato sparingly and treats it predominantly as ornamentation maintaining a consistent speed and narrow width when it is used. Shifting remains clean throughout. As a consequence of his continued use of period instruments and techniques, both performances present similar tone quality.

In general however, Bylsma's 1992 performance displays much more rhythmic freedom than the earlier one from 1979. Excluding the Prelude, the remaining five movements are performed at a slower tempo. Of these, the Allemande shows the most dramatic change in tempo (17\%) and rhythm. When examined side by side, it can be seen that Bylsma's later performance displays a noticeable increase in rhythmic flexibility (see Figure 3 and audio sample 3 ). The extremely slow and varied tempo lends the movement a more improvisatory feel in which scalar groupings are treated more as ornamentation rather than melodic figures.

Bylsma's 1992 performance also begins to make use of longer, more sustained note lengths executed with a softer attack. In the Courante, Sarabande, Gavottes and Gigue, the occasional use of this more extended stroke serves to disrupt the strict rhythmic feel that characterises the 1979 performance. Similarly, with the softer attack, chords are generally divided into two halves with the bottom half of the chord landing either on, or before the beat. This creates a sense of yet more rhythmic flexibility.

While Bylsma maintains certain fundamental aspects of the HIP tradition, differences can be observed in the slowing of tempi, an increase in rhythmic flexibility, and, especially, in the use of a more 
sustained bow stroke. Despite his solid foundations in the HIP style, Bylsma appears to display an awareness of changing MS approaches.

In the 1992 recording there is a marked increase in the amount of time spent on longer notes (e.g. tied quarter note, eighth notes and dotted sixteenth), while short notes (all others) continue to be performed at a fast pace. This contributes to the improvisatory nature of the 1992 performance

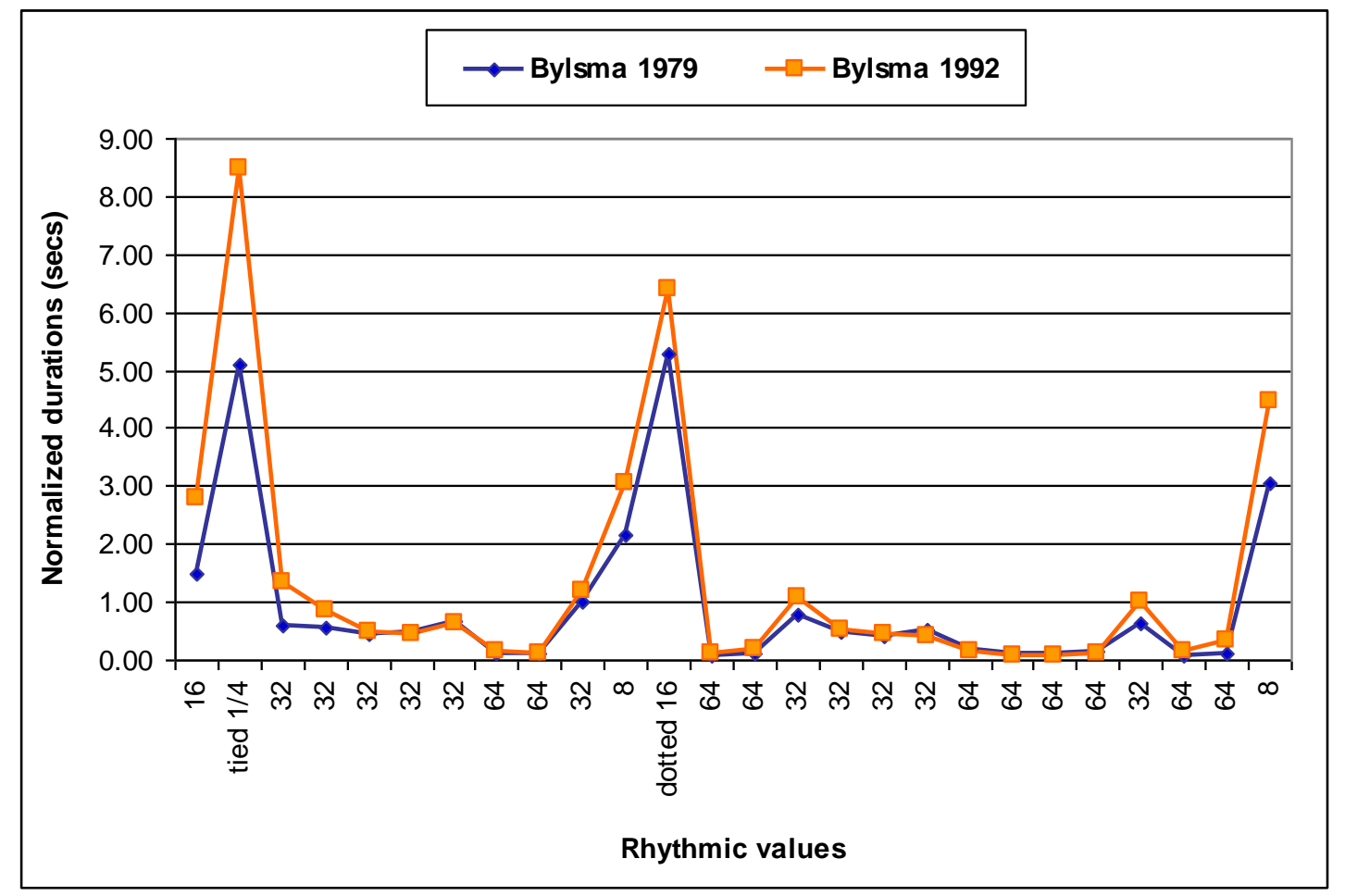

Figure 3. Rhythmic flexibility in Bylsma's two recordings of the Allemande (bar 1).

\section{YO-YO MA (1955 - )}

Both of Ma's 1983 and 1995 [MS] performances maintain a consistent approach to vibrato speed and width. In general, the speed remains "steady" and the width continues to be narrow throughout (cf. Table 3 above). His vibrato is also fairly regular; for speed the standard deviation across the measured notes is .27 and .46 respectively while for depth only .05 in the earlier and .04 in the later recording.

In the 1995 performance there appears to be an attempt to soften the attack of the bow stroke and relax the overall feel with more time spent on phrasing and articulation. This is aided by the slower speed at which all of the movements, except the Gigue, are performed (cf. Table 1 earlier). The slower tempi (especially in the Allemande and Sarabande where the difference is $12 \%$ and $15 \%$, respectively) and increased rhythmic flexibility allow for more dynamic variety. The combined effect of these dynamic and rhythmic choices in the 1995 performance focuses the attention on melodic phrasing and further contributes to the unhurried nature of the performance.

Importantly, Ma shows an obvious awareness of HIP techniques and conventions. For his 1995 performance, he uses Baroque tuning and a Baroque bow hold (Eisler, 2001). The looser strings and altered bow hold affect the overall timbre of the instrument. The note lengths are generally reduced while the bow stroke becomes lighter. There is also a move away from block chords in favour of rolled chords (audio sample 4), an interpretation that is claimed to be typical of eighteenth-century practice (Donington, 1989; Boyden, 1965).

While his second recording displays an adoption of HIP conventions in terms of his apparatus and bow stroke, it also moves toward a freely expressive and melodically, rather than rhythmically, orientated performance. 


\section{PIETER WISPELWEY (1965 - )}

Wispelwey's two [HIP] performances $(1990,1998)$ were recorded with the least amount of time between them among the samples selected for the current study. This may explain the strong similarities that they share. In addition to the obvious consistency of adopting performance conventions typical of HIP, Wispelwey's seemingly distinct approach to separating chords, most notable in the Gavotte, continues throughout both performances (audio sample 5).

Most apparent is a strong similarity in Wispelwey's approach to tempo and rhythm. Throughout both performances of the suite, his average tempi remain within four beats per minute (bpm) of each other with the Prelude having exactly the same average tempo and the Sarabande and the Gigue of the 1998 performance being only $1 \mathrm{bpm}$ faster than before. Furthermore, the plotting of measured rhythmic flexibility in the two versions of the Prelude (bars 1-12) illustrates the extent to which both performances match (Figure 4). Beyond maintaining the same tempo, Wispelwey also appears to follow an extremely similar plan with regard to rhythmic flexibility.

Despite this, differences can be recognised in the later performance. In the Allemande, both performances share a generally improvisatory character; however the later recording exaggerates this quality. The tempo is slower and as a result the sense of forward momentum is reduced. Additionally, the 1998 performance occasionally makes use of an altered bow stroke. Throughout the suite, Wispelwey uses a slightly heavier stroke in this later version with more pronounced articulation and shorter note lengths. This is noticed by Taruskin, too. He summarizes the differences between Wispelwey's two versions thus: "greater weight though far from heavy, a more focused outlook, more adult all around. And his virtuosity is not just showy now, but masterly. The ... Sixth Suite ... this time emerges as a set of stately and graceful dances, not an agonizing bout on the potty" ([sic] Taruskin, 2009b, p. 70).

Whether due to the shorter amount of time between recordings or a growing conviction in his original artistic motives, the performances share a strong resemblance. Wispelwey has suggested that he was "more experienced and less intimidated by the microphone" when making his second recording. It seems he felt a clear desire to re-record the suites in order to present a "livelier, freer and more expressive" performance (Anzon, 1997). Despite this, the differences that do exist between the recordings are most noticeable in the slight increases in rhythmic freedom and a weightier articulation and bow stroke.

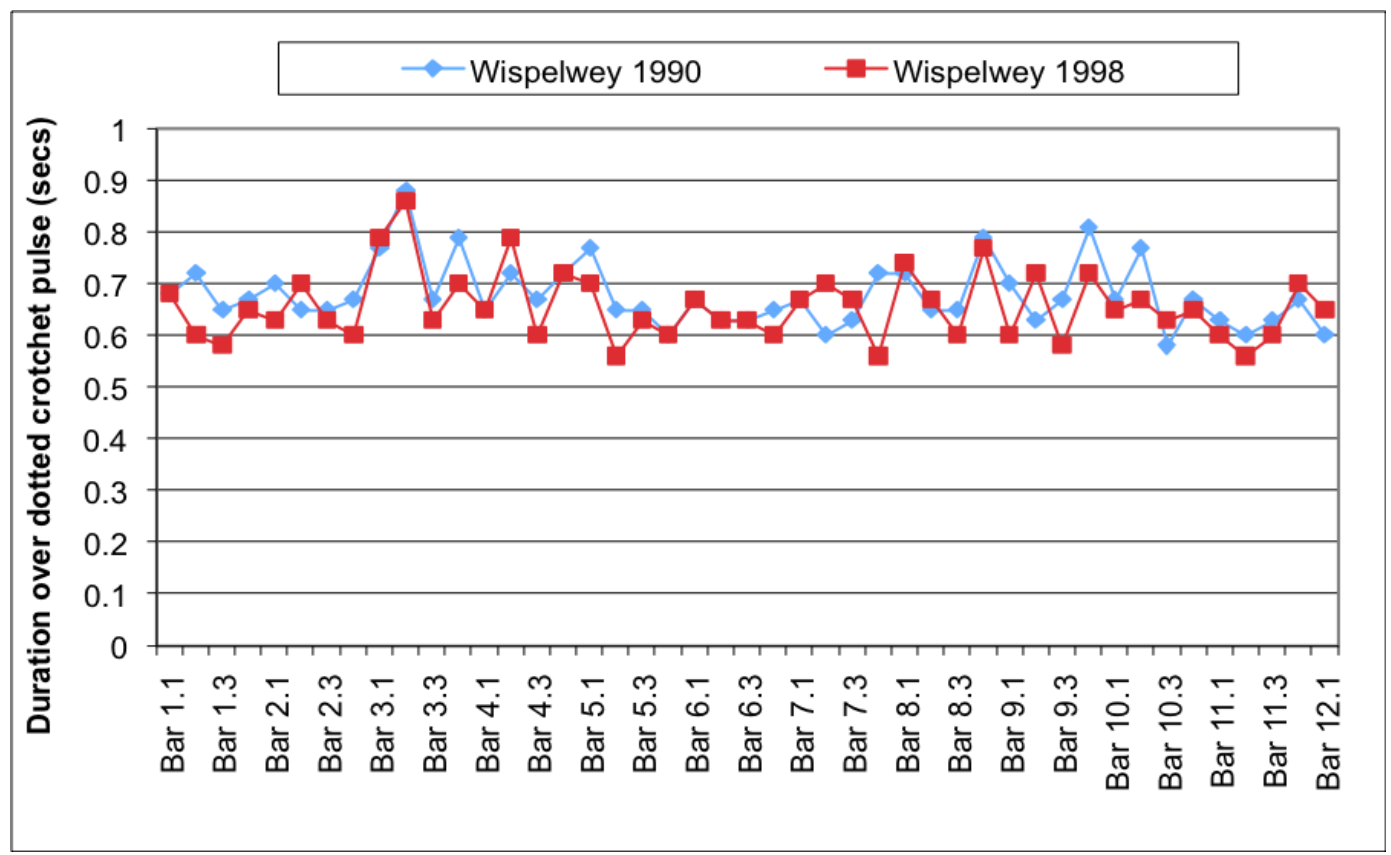

Figure 4. Rhythmic flexibility in Wispelwey's two recordings of the Prelude (bars 1-12). 


\section{Individuals and Broader Cultural Trends}

In the earlier performances, there is certainly evidence to suggest the presence of the depersonalised and geometric style of playing that Taruskin equates with the modern. Starker maintains an almost metronomic approach to rhythmic accuracy while Tortelier displays a strong, weighted and full bow stroke that varies little across all movements. For Starker, whose earliest teacher Adolf Schiffer is said to have discouraged and dismissed theatricality "as fitting for clowns to employ in lieu of talent" (Starker, 2004, p. 270), this is not surprising. In 1946, Starker experienced a period of deep critical analysis in which he came to question his own abilities and of which he later said, "I nearly had a nervous breakdown" (Starker, 2004). What emerged from this period was a new, technically grounded style of playing with, as Campbell notes, "perfection as his ultimate goal" (Campbell, 1988, p. 228). Thus his depersonalised performance style could be attributed to his own personal experiences as much as to the influence of a changing Zeitgeist. How important these formative years and ideologies may be for an artist's entire professional life can be demonstrated by observing the relatively minor change between his interpretations and certain distinctive elements typical of his playing as well as that of the era during which he launched his career. His playing has remained distanced from the growing influence of HIP aesthetics by maintaining a continuous vibrato, relatively slow tempo, even tone and long-range phrasing. Even so, there are aspects of his playing that seem to display certain characteristics of the HIP style. By the time of his later recording, his bow stroke has become noticeably lighter and there are increasing amounts of silence as notes are allowed to decay. That even his distinctively MS approach shows an awareness of HIP characteristics is testament to the impact that HIP had garnered by the early 1990s.

Tortelier, the oldest of all the surveyed performers, maintains extremely strong performance characteristics in his recordings. Apart from the distinctly consistent and heavy bow stroke, he also maintains a relatively wide vibrato. Both these features seem to actively reject the influences of the HIP aesthetic. It is not surprising that this should be the case. Having established his career in the pre-war era as well as sharing a long-lasting friendship with Casals (who, in the 1930s laid the foundations for the performance of the Suites in the $20^{\text {th }}$ century), it is more than likely that Tortelier would have held strong convictions about his established performance style (The Economist, 1990, August 25, p. 75). His interpretations could even be described as displaying notable signs of "romantic" expression. There is a focus on melodic content and uninterrupted long lines shaped primarily by long range fluctuations of dynamics. Vibrato is used liberally and expressive portamento can also be heard occasionally. The tone is even and seamlessly projected. According to Dunsby (1995, p. 50), many sources observe "that the 'romantic' is evident in every cultural 'period', and that ours is no exception". If this is the case then the romantically expressive tendencies of Tortelier's earlier performance should not be denied.

For these two performers, who each forged their careers in pre-WW2 Europe, it could be suggested that the influences of a modernist style of playing is evident within their early recordings but that they each present distinct and contrasting branches of the same modernist tradition. On one hand, Starker appears to display a more literal strand of modernism while Tortelier presents a more romantic strand. Several authors allude to the dualistic aspects of modernism. Both Born (1955) and Butt (2002, p. 126) point to the modernist tendency to oscillate between "rationalism and irrationalism, objectivism and subjectivism" and it is in this sense that the two performances can be considered modern. This strong dualist element of modernism can be clearly observed in the seemingly contrasting early performances of Starker and Tortelier.

Bylsma's recordings are interesting for the fact that they both seem to show an acute awareness of broader MS performance conventions whilst still presenting a contrast to them. In his 1979 recording, one of the earliest recorded performances of the Bach suites on a period instrument, Bylsma displays a consistent tempo and a strict approach to rhythm across all movements which make comparisons to the early MS recordings inevitable. Perhaps searching for a level of legitimacy, his earlier recording appears to reference the more literal readings observed in recordings by Tortelier and Starker. In this regard, it could be said that his interpretation reflects Taruskin's conception of a typically modernist interpretation. Yet as Butt (2002) has shown, the very exercise of creating a HIP performance is inherently postmodern. Bylsma's early recording clearly exemplifies Butt's summation of the HIP movement. While undoubtedly modern in its origins and aesthetic, it reflects a kind of "blind historicism" (Butt, 2002, p. 160) in which the past is duplicated and imitated but never really separated from the present. By 1992, Bylsma is using increased rhythmic flexibility testifying to the more "speaking quality" of the later HIP style. At the same time, however, his bow strokes have become more sustained which shows, in turn, the ongoing influence of the 
broader MS style. Bylsma is a contemporary of Harnoncourt, Leonhardt and Schroeder, the first generation of musicians promoting the cause of HIP after the Second World War. How much and what aspects of HIP practice and ideology they embraced and incorporated in their playing style seems to have depended not just on their personal conviction but also on their musical upbringing. Perhaps it is because he still plays in both styles (Sherman, 1997, p. 209) that Bylsma's performances show such a mixture of sensibilities to various performance trends.

If Bylsma may be regarded a HIP player demonstrating MS stylistic features and reflecting the modernist trend of his formative years in the 1940s and 1950s, Ma could be regarded as his counterpart: a representative of a younger generation of MS players who have embraced key aspects of the HIP style in place of the depersonalised, literal performances characteristic of the 1960s to 1980s. In the process they have created a mixed performance style which reflects the notion of a postmodern pluralism.

In his earlier recording Ma already appears to have taken on the narrower vibrato that pervades HIP recordings. With his later version, Ma's tempi slow considerably, just as the HIP players show slowing across most movements of the suite. From a purely technical point of view, Ma's use of some expressive shifting (portamento) and a moderate vibrato perhaps displays his foundations in the MS romanticmodernist school of playing. Yet he also shows a strong recognition of HIP conventions by adopting, in the later recording, Baroque tuning and an altered bow hold. While this in and of itself demonstrates the most obvious synthesis of MS and HIP conventions, Ma's overall approach to the suites substantiates his postmodern credentials. For his 1995 recording he undertook a series of collaborations with a range of artists including ice skaters, a film director, landscape designers, and dancers. In his own words, "Each collaboration lasted about two years and saw the development of artistic and personal trust which led to creative innovations" (Ma, 1997, p. 4); each resulting in a new approach to the performance of Bach's suites. Just as in Lyotard's "language games", the interaction of seemingly disparate discourses results in the creation of something new. When it is considered that Ma completed a liberal arts degree before fully committing to his career as a soloist, it becomes plausible to suggest that he would be aware of the broad changes occurring in Western culture. Ma's apparent cultural awareness is further confirmed by the comments he makes in the sleeve notes to the 1995 recording: "We live in a time when a tremendous amount of cultural information is available, and we have to re-examine constantly what is worth transmitting" (Ma, 1997, p. 5). It is little wonder then, that he would have taken on so many of the HIP conventions which, by 1995, had become so well recognised and appreciated by musicians and listeners world wide.

As has been stated, Wispelwey displays little change from his first recording to his second apart from perhaps making things more convincing and refined. Throughout both performances, he maintains many HIP conventions including a short bow stroke and a similar approach to tempo and rhythm. It has already been suggested that this might be due to the limited amount of time between performances or a growing conviction in his original artistic intentions and better command of their execution. Given his nationality and age - being the youngest of the cellists studied and coming from the Netherlands, the bedrock of HIP-his musical upbringing must have been steeped in postmodernist aesthetics and post 1980s HIP thinking that seems still current and not under revision. From the context of this discussion it might therefore be proposed that by the time of his recordings, the HIP style had established itself as the dominant performance style with regard to works from the Baroque. To quote Taruskin (2009b, p. 70) yet again, "I sense that Wispelwey has replaced Ma as the most influential model for budding cellists in this repertoire, and that is altogether to the good." However, this might also mean that the HIP style, which had constructed itself as an alternative and reaction to the mainstream, no longer holds minority status and as a consequence it has little to react to. While this provides a straightforward explanation, it is perhaps too simplistic to attribute the similarities in his two recordings to a single cause. More realistically, the resemblances in Wispelwey's two versions can probably be attributed to a combination of all of the suggested reasons.

\section{CONCLUSIONS}

Analysis of recorded performances can be brought short by an inability to distinguish between decisions that are informed by the performer's own stylistic intentions and those that have been influenced by broader external trends (Bowen, 1996). By comparing two recordings of Bach's Sixth Suite by the same performer, it has been possible to construct profiles of each performer so as to better understand how each might have 
responded to broader musical and cultural trends. By complementing these individual analyses with comparative investigations, each performer's idiosyncratic features could be distinguished from the elements that are more likely to have been influenced by external trends.

In the case of Tortelier and Starker, two MS performers who forged their careers in the pre-WW2 era, it can be seen that they each possess distinctive technical qualities which have a strong effect on their overall performances. While the other performers each maintain certain technical elements, the distinctly weighted bow stroke of Tortelier, and Starker's prominent vibrato make their performances easily identifiable.

With Bylsma and Wispelwey, the two performers aligned with the HIP movement, there are a number of technical elements that remain constant. Vibrato is used sparingly and remains narrow, tone quality is consistent, and shifting is limited (more use of open strings) and clean. Interestingly, Bylsma shows generally more variety between his performances. It is arguable whether his earlier or later recording represents a more typical HIP style. This is important, because it exemplifies the change between the preand post-1980s HIP trends. The former has been decried "modernist" by Taruskin (1995), "mechanical" by Dreyfus (1983) and "blind historicist" by Butt (2002) because of its similarities with contemporary MS styles that are characterized as "literal" and "depersonalized". In the later recording Bylsma's dramatically slower tempi, increased rhythmic flexibility, and softer, more sustained bow strokes project a generally more relaxed and improvisatory approach which may reflect the more subjective and expressive style that Dulak (1993) and others talk about as emerging since the late 1980s. While Taruskin (2009b, p. 69) hails this second interpretation for its sonorities and speaking quality, other HIP advocates referred to by Taruskin in his review apparently find Bylsma's second recording to display concessions to MS practice because of its liberties with tempo, meter, and more sustained bow strokes. These opposing opinions underscore the blending of styles that, at the same time, create opportunity for more individual interpretations that are neither clearly HIP nor MS.

In terms of general trends, considerable interaction between MS and HIP styles has been revealed. Given the substantial growth and popularity of the HIP movement during this period, it is not surprising that MS performers, especially Ma, tend to show a growing awareness of HIP conventions. Ornoy (2006, p. 243), through a comparative study of MS and HIP recordings alluded to "the high status of "historically informed' performances as authorities dictating their own interpretations to other tangent musical arenas". This has certainly shown itself to be true. However, the extent to which the two performance styles (as currently practised) share a common rejection of previous approaches should not be overlooked. By the 1990s, both MS and HIP players move away from strict, literalist readings of the Sixth Suite that dominate earlier performances. Both styles generally show a tendency to embrace greater rhythmic freedoms and a softer, lighter bow stroke. Therefore it could be argued that these two, seemingly disparate playing styles have interacted to create new approaches to performance that are less rigid or rule based and thus foster individual and idiosyncratic choices. Nevertheless, differences between MS and HIP can still be discerned. The former remains focused on melodic content and phrasing while the latter harnesses the resonance of the period instrument with its different setup (e.g. gut strings, short bow) and playing conventions (e.g. use of low positions and open strings) and focuses on projecting the harmonic foundations and rhythmic character of the dances.

While broad trends have undoubtedly emerged over the period, it would be an overstatement to suggest that there has emerged a single homogenous performance style, at least in relation to this repertoire. The 1990s demonstrate the strongest postmodernist tendencies in interpretations of Bach's Sixth Suite for Solo Cello. The HIP experiment, whilst ultimately shown to be a thoroughly contemporary response to the past, brought new approaches to performance. The interaction of the differing MS and HIP playing styles resulted in a new and diverse range of approaches to performance and thus exemplify the postmodern quest for plurality and diversity. As with most studies of trends within music performance, there are inevitable exceptions. Through carrying out detailed analysis of each individual recording, the importance of idiosyncratic performance characteristics could be demonstrated as a significant factor in showing both resistance and submission to broader trends. All performers maintain certain aspects of their own playing style which either reject or further contribute to the forming of such trends. 


\section{NOTES}

[1] To summarise briefly and rather crudely the main tenets of a large body of literature referred to in this section, a thumbnail definition of terms as they have been applied to music performance is provided. "Modern" or "modernist" refers to a performance style that aims for a beauty of tone and considers the performer to be a "vessel" for the composer's music "to speak for itself" (Taruskin, 1982). In this aesthetic, the ideal beauty of tone is evenness and it is achieved by well regulated vibrato that smooths out potential differences in timbre and register. Evenness is also the aim in all other technical matters. Therefore the primary articulation is legato, inflections are kept to a minimum, tempo is steady, and all markings of the score are meticulously observed and nothing more is added. This style, which is essentially literal, gained momentum by the 1930s and eventually developed to be the mainstream (MS) style throughout the 1950s to the end of the 1980s across the repertoire of Western classical music (Haynes, 2007). Originally HIP was cultivated in opposition to MS, fostering the use of period instruments and a recreation of period performing conventions. However, during the period from the 1950 s to the 1970 s, there was an overemphasis on "rules"; performance decisions were justified by citations from historical treatises or archival documents and some practitioners seemed to believe that as long as they played on a period instrument (or a copy thereof) their performance was historically "authentic" (Fabian, 2003). This practice, which may be referred to as "blind historicism" (e.g. Butt, 2002), was Taruskin's target and he successfully demonstrated its similarities to the literalist-modernist MS style. Although these views are still widely held as applicable to the current scene, performers have moved on since. Whether as a response to the criticism, or more likely, as a reaction of a younger generation to their forebears, the current generation of performers tend to present a more personal style of playing, enriched by freely added ornamentation, inflections, varied articulation and the like, which also reflect the pluralism of our age and thus can be labelled "postmodern." Since the 1990s the rhetoric of HIP has mellowed (Butt, 1999; Dulak, 1993; Sherman, 1997). Period instrumentalists seem to have been at the forefront of this apparent quest for pluralism and subjectivity as the whole HIP aesthetic gained momentum worldwide influencing younger MS players to adopt HIP principles when playing Baroque music. Our paper aims to explore these stylistic matters and their chronology to scrutinise these historical accounts and clarify possible differences and contradictions.

[2] Centre for Digital Music, Queen Mary, University of London, Sonic Visualiser, 2007, Accessed 3 March 2010. http://www.sonicvisualiser.org/. This software is starting to become the "industry standard" in performance analyses of recorded music.

[3] Visualization Software LLC, site of download ceased to exist

[4] A spectrogram displays what the ear hears: time along the horizontal axis, frequency (pitch) in $\mathrm{Hz}$ on the vertical axis. Different magnitudes of visualization enable the close inspection of vibrato waves and reading off exact values of time (in milliseconds) and frequency (in $\mathrm{Hz}, 4$ digits).

[5] We are grateful to Joe Wolfe, professor of physics and leader of the acoustics group at the University of New South Wales (see http://www.phys.unsw.edu.au/music/) for this equation.

[6] $R^{2}$ is a measure of variance explained (Urdan, 2005, p. 155).

[7] Richard Miller, with reference to vocal technique, suggests that a vibrato speed of around 6 cycles per second is considered steady or natural (Miller, 2000, p. 69). This is corroborated by others (e.g. Seashore, 1932; 1936; Prame, 1992). Based on close study of many artists' vibrato by different researchers (e.g. Fabian \& Ornoy, 2009; Leech-Wilkinson, 2009), this observation seems to hold true across various instruments.

\section{ACKNOWLEDGEMENT}

This research has been supported by an Australian Research Council Discovery grant (DP0879616). The authors wish to thank two anonymous reviewers for their constructive and valuable comments and suggestions. 


\section{REFERENCES}

Anzon, P. (1997). Pieter Wispelwey - Interview. La Scena Musicale, Vol. 3, No. 4. Retrieved 2011 April 10 from http://www.scena.org/lsm/sm3-4/sm3-4wispelwey-en.htm

Bazzana, K. (1997). Glenn Gould: The Performer in the Work. New York: Oxford University Press.

Born, G. (1955). Rationalizing Culture: IRCAM, Boulez, and the Institutionalization of the Musical AvantGarde. London: University of California Press.

Bowen, J.A. (1996). Performance practice versus performance analysis: Why should performers study performance? Performance Practice Review, Vol. 9, No. 1, pp. 16-35.

Boyden, D. (1965). The History of Violin Playing from its Origins to 1761. Oxford: Oxford University Press.

Butt, J. (1999). Bach recordings since 1980: A mirror of historical performance. In D. Schulenberg (Ed.), Bach Perspectives 4. Lincoln: University of Nebraska Press, pp. 181-198.

Butt, J. (2002). Playing with History: The Historical Approach to Musical Performance. Cambridge: Cambridge University Press.

Campbell, M. (1988). The Great Cellists. London: Gollancz.

Chaffin, R., Lemieux, A.F., \& Chen, C. (2007). "It is different each time I play": Variability in highly prepared musical performance. Music Perception, Vol. 24, No. 5, pp. 455-472.

Chaffin, R., Imreh, G., \& Crawford, M. (2002). Practicing Perfection: Memory and Piano Performance. Mahwah, NJ: Erlbaum.

Clarke, E.F. (1995). Expression in performance: Generativity, perception and semiosis. In J. Rink (Ed.), The Practice of Performance. Cambridge: Cambridge University Press, pp. 21-54.

Day, T. (2000). A Century of Recorded Music: Listening to Music History. New Haven: Yale University Press.

Donington, R. (1989). The Interpretation of Early Music (revised paperback edition). London: Faber \& Faber.

Dreyfus, L. (1983). Early music defended against its devotees: A theory of historical performance in the twentieth century. The Musical Quarterly, Vol. 69, No. 3, pp. 297-322.

Dulak, M. (1993). The quiet metamorphosis of "early music". Repercussions, Vol. 2, No. 2, pp. 31-61.

Dunsby, J. (1995). Performing Music: Shared Concerns. New York: Oxford University Press.

Economist, The (1990). Saraband: Interview with Paul Tortelier. No Author. Vol. 316, Issue 7669, pp. 75-6. Retrieved 2010 March 4, Business Source Premier. Accession number: 9009172169.

Eisler, E. (2001). Continuity in Diversity. Strings Magazine, Issue 94, (May/June), Retrieved 2010 April 12 from http://www.stringsmagazine.com/issues/strings94/toc.shtml (by subscription)

Fabian, D. (2003). Bach Performance Practice, 1945-1975: A Comprehensive Review of Sound Recordings and Literature. Aldershot: Ashgate. 
Fabian, D. (2005). Towards a performance history of Bach's sonatas and partitas for solo violin: Preliminary investigations. In L. Vikárius \& V. Lampert (Eds.), Essays in Honor of László Somfai: Studies in the Sources and the Interpretation of Music. Lanham, Maryland: Scarecrow Press, pp. 87-108.

Fabian, D. (2006). Is diversity in musical performance truly in decline? The evidence of sound recordings. Context, Vol. 31, pp. 165-180.

Fabian, D. (2008). Classical sound recordings and live performances: Artistic and analytical perspectives. In M. Dogantan-Dack (Ed.), Recorded Music: Philosophical and Critical Reflections. London: Middlesex University Press, pp. 232-260.

Fabian, D., \& Ornoy, E. (2009). Identity in violin playing on records: interpretation profiles in recordings of solo Bach by early twentieth-century violinists. Performance Practice Review, Vol. 14, pp. 1-40.

Gramophone (1984). Bach: Solo Cello Suites Nos. 1-6, BWV1007-12. Yo-Yo Ma. CBS Masterworks. Review by N. A. (June), p. 55. Retrieved 2011 January 27 from http://www.gramophone.net/Issue/Page/June\%201984/55/779956/BACH

Gramophone (1999). Reputations: János Starker. No author. (August), pp. 39-42. Retrieved 2011 January 27 from http://www.gramophone.net/Issue/Page/August\%201999/39/803266/Reputations

Haynes, D. (2007). The End of Early Music: A Period Performer's History of Music for the Twenty-First Century. New York: Oxford University Press.

Hong, J.-L. (2003). Investigating expressive timing and dynamics in recorded cello performances. Psychology of Music, Vol. 31, No. 3, pp. 340-352.

Jameson, F. (1991). Postmodernism, or, the Cultural Logic of Late Capitalism. Durham, NC: Duke University Press.

Katz, M. (2004). Capturing sound: How Technology has Changed Music. Berkeley: University of California Press.

Katz, M. (2006). Portamento and the phonograph effect. Journal of Musicological Research, Vol. 25, No. 3-4, pp. 211-232.

Kenyon, N. (Ed.) (1988). Authenticity and Early Music. Oxford: Oxford University Press.

Laird, P. (2004). The Baroque Cello Revival: An Oral History. Lanham, MD: Scarecrow Press.

Lawson, C. \& Stowell, R. (1999). Historical Performance: An Introduction. Cambridge: Cambridge University Press.

Leech-Wilkinson, D. (2006). Portamento and musical meaning. Journal of Musicological Research, Vol. 25, No. 3-4, pp. 233-261.

Leech-Wilkinson, D. (2009). The Changing Sound of Music: Approaches to Studying Recorded Musical Performance. London: CHARM. Retrieved 2009 October 5 from http://www.charm.rhul.ac.uk/studies/chapters/intro.html

Leech-Wilkinson, D. (2010). Recordings and histories of performance style. In N. Cook, E. Clarke, D. Leech-Wilkinson, \& J. Rink (Eds.), The Cambridge Companion to Recorded Music. Cambridge: Cambridge University Press, pp. 246-62.

Levitin, D.J., \& Cook, P.R. (1996). Memory for musical tempo: Additional evidence that auditory memory is absolute. Perception \& Psychophysics, Vol. 58, No. 6, pp. 927-935. 
Lyotard, J.-F. (1994). The Postmodern Condition. [English trans. by Massumi and Bennington], Minneapolis: University of Minnesota Press.

Ma, Y.-Y. (1997). Yo-Yo Ma Inspired By Bach. [CD liner notes], New York: SONY Classical.

Miller, D. (2000). Training Soprano Voices. New York: Oxford University Press.

Milsom, D. (2003). Theory and Practice in Late Nineteenth-Century Violin Performance: An Examination of Style in Performance, 1850-1900. Aldershot: Ashgate.

Ornoy, E. (2006). Between theory and practice: comparative study of early music performances. Early Music, Vol. 34, No. 2, pp. 233-247.

Ornoy, E. (2008). Recording analysis of J.S. Bach's G minor adagio for solo violin (excerpt): A case study. Journal of Music and Meaning, 6, Retrieved 2009 November 6 from

http://www.musicandmeaning.net/issues/showArticle.php?artID=6.2

Philip, R. (1992). Early Recordings and Musical Style: Changing Tastes in Instrumental Performance, 1900-1950. Cambridge: Cambridge University Press.

Philip, R. (2004). Performing Music in the Age of Recording. New Haven: Yale University Press.

Prame, E. (1992). Measurements of the vibrato rate of 10 singers. Quarterly Status Report of the Department of Speech, Music and Hearing, KTH (STL-QPSR), Vol. 33, No. 4, pp. 73-86.

Repp, B.H. (1992). Diversity and commonality in music performance: An analysis of timing microstructure in Schumann's Träumerei. Journal of the Acoustical Society of America, Vol. 92, No. 5, pp. 2546-2568.

Repp, B.H. (1995). Quantitative effects of global tempo on expressive timing in music performance: Some perceptual evidence. Music Perception, Vol. 13, No. 1, pp. 39-57.

Seashore, C.E. (Ed.) (1932). The vibrato. University of Iowa Studies in the Psychology of Music. Vol. 1.

Seashore, C.E. (1936). Psychology of the vibrato in voice and instrument. University of Iowa Studies in the Psychology of Music. Vol. 3.

Shaffer, L.H., Clarke, E.F., \& Todd, N.P. (1985). Meter and rhythm in piano playing. Cognition, Vol. 20, No. 1, pp. 61-77.

Sheldon, D.A., \& Gregory, D. (1997). Perception of tempo modulation by listeners of different levels of educational experience. Journal of Research in Music Education, Vol. 45, No. 3, pp. 367-379.

Sherman, B.D. (1997). Inside Early Music: Conversations with Performers. New York: Oxford University Press.

Siblin, E. (2009). The Cello Suites: J.S. Bach, Pablo Casals and the Search for a Baroque Masterpiece. Melbourne: Allen and Unwin.

Starker, J. (2004). The World of Music According to Starker - A Memoir. Bloomington: Indiana University Press.

Spiro, N., Gold, N., \& Rink, J. (2010). The form of performance: Analyzing pattern distribution in select recordings of Chopin's Mazurka Op. 24 No. 2. Musicae Scientiae, Vol. 14, No. 2, pp. 23-52. 
Taruskin, R. (1982). On letting the music speak for itself: Some reflections on musicology and performance. Journal of Musicology, Vol. 1, No. 3, pp. 101-17.

Taruskin, R. (1995). Text and Act: Essays on Music and Performance. Oxford: Oxford University Press.

Taruskin, R. (2009a). Early music: Truly old-fashioned at last? In R. Taruskin, The Danger of Music and Other Anti-Utopian Essays. Berkeley: University of California Press, pp. 129-132. (Originally published in the New York Times, 14 June 1998.)

Taruskin, R. (2009b). Six times six: A Bach suite selection. In R. Taruskin, The Danger of Music and Other Anti-Utopian Essays. Berkeley: University of California Press, pp. 66-70. (Originally published in Strings 1995, Vol. 9, No. 4, pp. 117-21.)

Tortelier, P. (1984). A Self-Portrait: In Conversation with David Blum. London: Heinemann.

Urdan, T.C. (2005). Statistics in Plain English. New Jersey: Lawrence Erlbaum Associates Inc.

Winold, A. (2007). Bach's Cello Suites: Analyses and Explorations. Bloomington: Indiana University Press.

\section{DISCOGRAPHY}

Bylsma, A. (1979). Bach, J.S., Suites for Solo Cello. Vivarte SONY SBK 61812.

Bylsma, A. (1992). Bach, J.S., Suites for Solo Cello. Vivarte SONY S2K 48047.

Ma, Y.-Y. (1983). Bach, J.S., Suites for Solo Cello. Sony Classical SK 78751.

Ma, Y.-Y. (1995). Inspired by Bach: The 6 Cello Suites. Sony Classical SK 63203.

Starker, J. (1963). Bach, J.S., Suites for Solo Cello. Mercury 470644-2.

Starker, J. (1992). Bach, J.S., Suites for Solo Cello. BMG / RCA 09026-61436-2.

Tortelier, P. (1961). Bach, J.S., Suites for Solo Cello. EMI Classics 5690002.

Tortelier, P. (1982). Bach, J.S., Suites for Solo Cello. EMI Classics 2n28358 2.

Wispelwey, P. (1990). Bach, J.S., Suites for Solo Cello. Channel Classics CCS 109011.

Wispelwey, P. (1998). Bach, J.S., Suites for Solo Cello. Channel Classics CCS 12298.

\section{LIST OF AUDIO SAMPLES}

1. Tortelier, Prelude bars 1-12 1961 recording Tortelier, Prelude bars 1-12 1982 recording

2. Starker, Sarabande bars 9-16 1963 recording Starker, Sarabande bars 9-16 1992 recording

3. Bylsma, Allemande bar 11979 recording Bylsma, Allemande bar 11992 recording

4. Ma, Gavotte bars 1-8 1983 recording Ma, Gavotte bars 1-8 1995 recording

5. Wispelwey, Gavotte bars 1-8 1990 recording Wispelwey, Gavotte bars 1-8 1998 recording 